\title{
A GAROTA DINAMARQUESA: REFLEXÃO SOBRE O DIREITO FUNDAMENTAL À SEXUALIDADE
}

\author{
Luiza Helena Messias Soalheiro ${ }^{1}$ \\ Paula Oliveira Mascarenhas Cançado ${ }^{2}$
}

Resumo: Este artigo, que adota a metodologia de pesquisa bibliográfica, visa apresentar a visão geral sobre o livro A Garota Dinamarquesa e, a partir deste prisma, analisar a transexualidade. Para tanto, investiga-se conceitos elementares como gênero e identidade de gênero, levantandose reflexões que auxiliarão na melhor compreensão de quem são os transexuais. Em seguida, demonstra-se as dificuldades ainda hoje enfrentadas pelos transexuais, trazendo inclusive casos jurisprudenciais relacionados com o tema. Por fim, adotando-se uma visão civil constitucional, apresenta-se a efetivação dos direitos fundamentais, em especial, o direito fundamental à sexualidade como meio garantidor da autorregulamentação dos projetos de vidas.

Palavras-chave: Garota Dinamarquesa; Gênero; Transexualidade; Direito Fundamental; Direitos da personalidade.

\section{INTRODUÇÃO.}

O livro, A Garota Dinamarquesa, do autor David Ebershoff deu origem ao filme de mesmo nome, inspirado em uma história real, a qual relata a vida de um artista plástico dinamarquês que teria sido a primeira pessoa a realizar uma cirurgia de mudança de sexo. $\mathrm{O}$ cenário da história se desenvolve na década de 20 , momento em que a medicina da época possuía poucas condições técnicas e tecnológicas para lidar com as possíveis complicações

\footnotetext{
${ }^{1}$ PUC MINAS - Pontifícia Universidade Católica de Minas Gerais. Advogada. Professora. Mestre em Direito Privado pela Pontifícia Universidade Católica de Minas Gerais. Especialista em Direito de Família e Sucessões pela Faculdade Arnaldo Janssen. Graduada pelo Centro Universitário Newton Paiva. Email:luizasoalheiro@hotmail.com.

2 Universidade de Itaúna. Graduada em Direito pela Pontifícia Universidade Católica de Minas Gerais (2009). Advogada. Pós graduada em Direito Civil e Processual Civil: Teoria e Prática pela UniSEB (2011). Mestre em Proteção dos Direitos Fundamentais pela Fundação Universidade de Itaúna (2014). Instrutora de Direito Civil e Direito Constitucional da Academia de Bombeiros Militar do Estado de Minas Gerais. Instrutora Credenciada, no ano de 2015, em Direito Civil e Constitucional da Academia de Polícia Militar do Estado de Minas Gerais. Professora de Direito Constitucional da Faculdade de Direito de Contagem (FDCON). E-mail: paulaomcancado@gmail.com
} 
decorrentes daquela intervenção. Talvez por isso, tenha sido um marco histórico para a medicina e, especialmente, uma brecha para a discussão dos transexuais.

A partir da análise do livro e do próprio filme, apresentar-se-ão conceitos elementares e discussões relevantes para a compreensão da transexualidade, levantando-se questionamentos como se é possível o enquadramento de todas as pessoas nos mesmos padrões de comportamento? Ou, ainda, existe apenas uma forma de identidade?

O enredo do livro demonstra justamente a angústia da personagem principal ao não se identificar com o seu próprio corpo. O sofrimento com aquela situação é tamanho que o leva a buscar todas as soluções para tentar resolvê-lo. Contudo, sua realidade foi encarada como uma doença, sendo inclusive diagnosticado com esquizofrenia antes de passar pelo procedimento cirúrgico que contribuiu para o fortalecimento da identificação de Lili.

Em que pese a história do livro tenha se passado há décadas, o presente artigo demonstrará que ainda hoje há muita violência e preconceito direcionados a tudo aquilo que foge à "normalidade" imposta pela sociedade. Exigir, por exemplo, a realização de cirurgia de redesignação sexual do pintor Einar para a posterior efetuação da retificação do registro civil, não seria atitude semelhante como tratar os transexuais como esquizofrênicos, do jeito que foi tratada a personagem do livro A Garota Dinamarquesa? Daí a justificativa de se trazer à tona a discussão do tema.

Em seguida, embasando-se no Direito Civil Constitucional, verificar-se-á como a efetivação dos direitos fundamentais pode permitir a cada pessoa o exercício da autonomia privada, ou seja, a possibilidade de autorregulamentação da própria vida, o que pode passar pela construção de um projeto de vida em que sua identidade de gênero seja socialmente respeitada como um exercício do direito fundamental à sexualidade.

\section{A SEXUALIDADE COMO DIREITO FUNDAMENTAL.}

Gênero é uma construção social que demarca determinados padrões de comportamentos e atitudes para as pessoas de acordo com os seus órgãos sexuais. Assim, aquele que nasce com pênis é considerado homem, enquanto quem nasce com vagina é considerado mulher (BARROS, 2016). 
O gênero é construído socialmente e, em regra, espera-se que meninos e meninas, já na infância ou na adolescência, confirmem o seu gênero, de acordo com o seu sexo biológico, por meio de atitudes e comportamentos tidos como "normais" para homens ou para as mulheres.

A lógica acima explicada é da heteronormatividade, ou seja, o “desejável” é a heterossexualidade e a identificação do gênero com o sexo biológico. De acordo com Lohana Santos (2016), a ideia é a fabricação do entendimento de que as pessoas, como um todo, nascem naturalmente assim e, o que se espera, é que a vida se reproduza de acordo com padrões previamente estabelecidos.

A construção do gênero está tão arraigada na cultura, que ela é reproduzida, muitas vezes, sem que aquele que a reproduz esteja consciente dessa reprodução.

Caso você seja convidado para uma festa de aniversário de uma menina que comemorará seu quinto aniversário, possivelmente, achará normal presenteá-la com bonecas, carrinhos de bonecas e panelinhas cor de rosa. Você, provavelmente, não comprará carrinhos ou armas de brinquedo, afinal, esses seriam presentes para meninos.

Perceba que o exemplo acima também tem por objetivo demonstrar que se espera da mulher o desenvolvimento de habilidades domésticas como saber cozinhar, cuidar da casa e dos filhos, enquanto esses comportamentos são menos (ou não são) estimulados nos homens e, assim, a identidade de gênero, entendida como as percepções que se tem sobre o gênero, vai sendo construída (BARROS, 2016).

Recentemente, em um chá de bebê, uma amiga contava que, há um ano e meio, passou a morar junto com o noivo. Essa amiga, aconselhava as outras que ainda iriam se casar a não se assustarem com o fato de que os homens não são proativos nas atividades domésticas, afinal, eles não aprenderam, como as mulheres, desde pequenas, a se perceberem como responsáveis pelos afazeres da casa. Para concluir, essa amiga disse às demais: "não fiquem muito estressadas, senão, vocês não se casarão com homem nenhum".

A identidade de gênero não é um dado posto e acabado, mas uma construção que sofre as influências de cada tempo. De acordo com Jaqueline Gomes de Jesus:

Mulheres de países nórdicos têm características que, para nossa cultura, são tidas como masculinas. Ser masculino no Brasil é diferente do que é ser masculino no Japão ou mesmo na Argentina. Há culturas para as quais não é o órgão genital que define o sexo. Ser masculino ou feminino, homem ou mulher, é uma questão de gênero. Logo, o conceito básico para entendermos homens e mulheres é o de gênero (JESUS, 2012). 
E ainda:

Sexo é biológico, gênero é social, construído pelas diferentes culturas. E o gênero vai além do sexo: o que importa, na definição do que é ser homem ou mulher, não são os cromossomos ou a conformação genital, mas a auto-percepção e a forma como a pessoa se expressa socialmente (JESUS, 2012).

O que se espera dos homens e das mulheres de hoje é o mesmo que se esperava dos homens e das mulheres de trinta, cinquenta anos atrás? É possível o enquadramento de todas as pessoas nos mesmos padrões de comportamento? $\mathrm{Ou}$, ainda, existe apenas uma forma de identidade?

O transexual é, justamente, um exemplo daquele que "não se identifica com o gênero que lhe foi atribuído ao nascer" e, assim, não se encaixa no padrão de comportamento que lhe é esperado, pois, por exemplo, apesar de ter órgãos sexuais masculinos, percebe-se como mulher (BARROS, 2016, p. 88). O importante, neste momento, é perceber que aqueles conhecidos como trans ou transgêneros (transexuais e travestis) vivenciam uma questão de identidade e não um transtorno (JESUS, 2012).

Dentro deste contexto, pode-se citar como exemplo o sofrimento vivenciado pela personagem principal do livro A Garota Dinamarquesa, no momento em que Einer Wegener foi realizar uma de suas consultas e o médico informou que era necessário interná-lo, haja vista a suspeita de esquizofrenia: “Ele queria que eu assinasse os papeis da internação ali mesmo. Mas isso não está certo. Eu não sou esquizofrênico. Eu disse que não havia tanta urgência. Mas você não acha que eu sou esquizofrênico, acha? Isso não tem lógica alguma”. (EBERSHOFF, 2016, P. 197) O questionamento feito por Einer a sua esposa foi respondido prontamente: "Não acho não. Mas quando você explica a coisa... quando você explica Lili, realmente, parece que você acha que existem duas pessoas. Duas pessoas diferentes”. (EBERSHOFF, 2016, P. 197)

Em outra consulta, um novo médico questiona a esposa de Einar sobre a possibilidade de conversar com o seu marido para alertá-lo quanto ao mal que estava fazendo a si próprio, afirmando que:

Trata-se de sanidade, a senhora não concorda? Não concorda que há algo de levemente insano nos desejos de seu marido? Que a senhora e eu, como cidadãos responsáveis, não podemos deixar seu marido perambular livremente por aí como Lili? Nem mesmo em Copenhague. Nem mesmo ocasionalmente. Nem mesmo sob a sua supervisão. Creio que a senhora concorda que devemos fazer tudo o que for preciso para tirar este 
demônio de dentro dele, porque se trata disso, a senhora não concorda? De um demônio. A senhora não concorda? (EBERSHOFF,2016, p. 136)

Como a transexualidade não é um transtorno, tem-se optado por este termo e não mais por transexualismo (o mesmo vale para o homossexualismo), já que "ismo" significa doença. Apesar desse entendimento, "a Classificação Internacional de Doenças (CID 10) ainda utiliza a palavra transexualismo, e não transexualidade" (ALVARENGA, 2016, p. 31).

Se gênero é uma questão de identidade, então, "a variedade de experiências humanas sobre como se identificar a partir de seu corpo (...) mostra ser possível haver homens com vaginas e mulheres com pênis". (JESUS, 2012).

Já o gênero não se confunde com orientação sexual, que diz respeito à atração afetivossexual, assim, uma pessoa trans pode ser bissexual, heterossexual ou homossexual (JESUS, 2012). A conclusão a que se chega é que não existe um padrão de identidade para os transexuais (SANTOS, 2016).

Da mesma forma que as questões referentes à sexualidade, ao gênero e à identidade de gênero passaram por releituras, no decorrer do tempo, o mesmo se pode afirmar com relação aos direitos fundamentais, que são entendidos como "verdadeiras conquistas evolutivas da sociedade" (ALMEIDA, 2008, p. 297). De fato, os direitos fundamentais estão em constante evolução e permitem aos seus titulares desenvolverem seus projetos de vida com dignidade (CANÇADO, 2014).

Para um transexual, a construção de um projeto digno de vida está atrelada a necessidade de assumir, socialmente, a sua identidade de gênero, a retificação do seu nome nos documentos oficiais e, caso queira, a cirurgia de transgenitalização.

$\mathrm{O}$ direito fundamental à igualdade, estampado no caput do artigo $5^{\circ}$ do texto constitucional, para ser interpretado em consonância com o constitucionalismo contemporâneo, requer diferenciar discriminação, entendida como aquela que é arbitrária ou abusiva, de diferenciação, adequada e razoável (FERNANDES, 2015).

Para que o princípio (ou direito fundamental) da igualdade seja efetivado, no caso dos transexuais, é adequado e razoável que o ordenamento jurídico lhes proporcione mecanismos necessários para que consigam viver de acordo com o que consideram uma vida digna.

A promoção do bem de todos sem preconceitos de sexo e quaisquer outras formas de discriminação constitui um objetivo fundamental da República Federativa do Brasil. De acordo 
com Almeida, os direitos fundamentais exigem interpretação aberta e ampliativa, o que significa que "cada direito fundamental, em si, merece interpretação aberta e flexível, sempre ampliativa" (ALMEIDA, 2008, p. 323).

Desta forma, a compreensão adequada do artigo $3^{\circ}$, IV da Constituição da República de 1988 é aquela que vai além da compreensão de que o artigo em comento apenas rechaça tratamentos desiguais vivenciados por mulheres em relação aos homens, para abranger, também, a proibição de discriminação em razão do sexo, no sentido de "representações e papeis culturalmente associados à masculinidade e à feminilidade". (RIOS, 2010, p.695).

Os direitos fundamentais, de acordo com Konrad Hesse (1998), devem ser compreendidos como princípios objetivos que obrigam o Estado a fazer o possível para realizalos.

Dimoulis e Martins (2009, p. 46), em obra especializada, definem os direitos fundamentais como "direitos público-subjetivos de pessoas (físicas ou jurídicas), contidos em dispositivos constitucionais e, portanto, que encerram caráter normativo supremo dentro do Estado, tendo como finalidade limitar o exercício do poder estatal em face da liberdade individual".

É importante perceber que os conceitos acima de direitos fundamentais, dos respeitáveis autores, merecem uma observação - está centralizado na relação que se estabelece entre as pessoas, físicas ou jurídicas, e o Estado.

Apesar de, na maioria das vezes, os discursos que envolvem os direitos fundamentais se apresentarem nessa dimensão vertical (Estado e o particular), há uma outra dimensão dos direitos fundamentais que não pode ser desprezada - a dimensão horizontal, que estabelece que as relações que são travadas entre os particulares também estão permeadas pelos direitos fundamentais.

A análise dos direitos fundamentais na dimensão vertical e horizontal não é meramente retórica, uma vez que possui consequências práticas.

A dimensão vertical dos direitos fundamentais estabelece para o Estado a obrigação de elaborar leis e desenvolver políticas públicas adequadas para a realização dos projetos de vida dos transexuais, como o estabelecimento do modo como se dará a retificação do registro civil, a realização, pelo Sistema Único de Saúde, da cirurgia de redesignação sexual, a inserção, nas escolas, de matérias que discutam os direitos fundamentais. 
Já a dimensão horizontal dos direitos fundamentais exige que os direitos dos transexuais sejam respeitados nas relações intersubjetivas que vierem a travar. Assim, dentro das relações familiares, de trabalho, de amizade, os transexuais devem ser respeitados no que tange à escolha de vida que fizeram. A dimensão horizontal dos direitos fundamentais é importante, porque também traz a responsabilidade de efetivação (ou violação) dos direitos fundamentais para todas as pessoas.

Não é apenas o Estado o responsável pela materialização dos direitos. A sociedade também o é. Assim, atitudes de deboche, de piadas maldosas, de exclusão, de agressões físicas consistem em flagrantes violações dos direitos fundamentais daquele que "não se identifica com o gênero que lhe foi atribuído ao nascer" (BARROS, 2016, p. 88).

\section{A GAROTA DINAMARQUESA: a transexualidade em cena}

O livro e o filme deixam claro o preconceito sofrido pela personagem principal, demonstrando a dificuldade da sociedade em aceitar o convívio com os transexuais. Contudo, ainda nos dias atuais, é visível este preconceito na sociedade, talvez porque em nossa cultura há sempre o estabelecimento de padrões de normalidade estereotipados.

A título de exemplo, o Catar, por decisão tomada pelo Ministério da Cultura, após protestos online proibiu a exibição do filme por considerá-lo “depravado" (BRASIL, 2016). Sim, no século XXI, com tamanha evolução tecnológica, aprofundado processo de globalização da economia e da informação ainda há muita censura, ao ponto de proibir a exibição de um filme que trata, ainda que de forma romântica, a transformação da vida de um transexual, como se essa proibição tivesse o poder de inibir a realidade latente da transexualidade.

Ocorre que as questões relacionadas ao gênero, como anteriormente explicado, estão ligadas à identidade de cada pessoa, o que pode fugir da "normalidade" imposta pela sociedade. Como explica Andrew Solomon, a dissonância de gênero pode se apresentar muito cedo:

Aos três ou quatro anos, as vezes menos, a criança pode perceber uma incongruência entre aquilo que lhe dizem que ela é e aquilo que ela sente ser. Essa incongruência é chamada de transtorno de identidade de gênero (TIG). Na primeira infância, a não conformidade de gênero muitas vezes é tolerada, mas por volta dos sete anos as crianças são forçadas a assumir estereótipos de gênero. As crianças trans podem 
reagir a essas pressões com ansiedade e depressão. Contar para os pais normalmente é terrível para elas (SOLOMON, 2013, p. 697).

De fato, em muitos casos, há a repressão das crianças com transtorno de identidade de gênero e, por vezes, nem sempre sendo diagnosticado o transtorno, em razão do medo dos pais tomarem conhecimento de que os filhos não são quem realmente aparentam ser, afastando-se do que seja "correto" para aquela família. Contudo, ignorar o assunto não é solução, é o que ensinam Juliana Alvarenga e Marcelo Couto:

Enquanto a questão do gênero não é resolvida o transexual se sente 'preso', como se uma âncora o impedisse de tocar sua vida para frente. Assim, outras questões também importantes para o desenvolvimento da personalidade acabam sendo relegadas a segundo plano. A imposição social de 'normalidade' repercute de forma bastante cruel nos indivíduos que não se identificam como parte de um grupo. No caso dos transexuais, geralmente o primeiro confronto se dá no âmbito familiar, quando os pais tentam 'educar' seus filhos ensinando o comportamento 'adequado' para um menino ou menina. Mas esta 'adequação' tem como referência o padrão social, e não a satisfação pessoal da criança (ALVARENÇA; COUTO, 2016, p. 101)

Associado a estes sofrimentos, os transexuais enfrentam na vida adulta outros entraves. Ainda não existe, por exemplo, um posicionamento uniforme se há necessidade ou não de o Poder Judiciário ter de autorizar a cirurgia de transgenitalização e de mudança de prenome, assim, os tribunais têm decidido de maneira conflitante. Observa-se:

APELAÇÃO CÍVEL. AÇÃO DE RETIFICAÇÃO DE REGISTRO DE NASCIMENTO QUANTO AO NOME E SEXO DO AUTOR. TRANSEXUALISMO. AUSÊNCIA DE CIRURGIA DE REDESIGNAÇÃO SEXUAL. INVIABILIDADE DA ALTERAÇÃO DO REGISTRO, UMA VEZ NÃO PREVISTA CIRURGIA PARA MUDANÇA DE SEXO, NEM MESMO PROVA ROBUSTA ACERCA DA ABRANGÊNCIA DO TRANSTORNO SEXUAL. APELAÇÃO DESPROVIDA (BRASIL, 2013) (Grifo nosso).

Em caso conhecido no Brasil, sobre a Roberta Close, antes de conseguir através de uma segunda ação judicial sentença favorável em 2005, houve parecer ministerial, acolhido pelo Tribunal de Justiça do Rio de Janeiro, negando seu pedido de reconhecimento como mulher, o qual descrevia ser "inviável a pretendida alteração de sexo natural, certo ser inadmissível pretender priorizar, sobre o mesmo, o chamado sexo psicológico, que representa, 
no fundo, uma pretensa explicação, para desvios da conduta, em razão de alteração anormal do psiquismo" (BRASIL, 1995).

Em que pese o Superior Tribunal de Justiça, cada vez mais, decidir favoravelmente às questões envolvendo registro civil e cirurgia de transexuais, ainda são comuns decisões judiciais, como as apresentadas acima, que levam em consideração estritamente o critério biológico.

Sem dúvida, "é preciso enxergar, de uma vez por todas, que a tutela dos direitos da personalidade funda-se no reconhecimento social, por meio da valorização positiva, na busca de respeito" (SÁ; NAVES, 2015, p. 333), a fim de se evitar decisões como estas que ferem o direito fundamental à sexualidade.

Apesar de ainda não existir um consenso de posicionamento do Judiciário brasileiro nas questões que envolvem os transexuais, é necessário que os Poderes Públicos cheguem ao entendimento de que, uma vez realizados todos os exames e acompanhamentos psicoterapêuticos $^{3}$, não cabe ao judiciário o reexame de tais procedimentos para autorizar ou não a cirurgia de redesignação sexual. Assim, constatada a transexualidade de uma paciente por uma equipe médica multidisciplinar, pode-se realizar o procedimento cirúrgico, independe de autorização judicial, como forma garantidora do exercício do direito à saúde:

Temos, então, que a cirurgia de mudança de sexo não é destrutiva, mas de índole corretiva, garantidora do livre desenvolvimento da personalidade do ser humano, possuindo o condão de adequar o sexo morfológico ao sexo psíquico do indivíduo. Não se pode olvidar que todos os exames devem ser procedidos para que não tenham dúvidas sobre a transexualidade do paciente, seja ela primária, seja secundária ${ }^{4}$ (SÁ; NAVES, 2015, p. 323).

\footnotetext{
${ }^{3}$ A portaria n ${ }^{\circ} 457$ de 19 de agosto de 2008 do Ministério da Saúde (Secretaria de Atenção à Saúde) inclusive prevê a necessidade de tratamento terapêutico pelo prazo mínimo de 2 anos, in verbis: "4. INDICAÇÕES DE CIRURGIA DE TRANSGENITALIZAÇÃO. A consideração da pertinência das intervenções médico-cirúrgicas devem atender aos critérios estipulados pela Resolução ${ }^{\circ}$ 1.652/2002 do CFM, que determinam o prazo mínimo de 2 anos de acompanhamento terapêutico como condição para a viabilização de cirurgia, bem como a maioridade e o diagnóstico de transexualismo. Transcorridos os dois anos de acompanhamento terapêutico, caso o usuário seja diagnosticado transexual, pela equipe multiproficional, está apto a se submeter à cirurgia de transgenitalização, o que não significa que deva necessariamente se submeter a este recurso terapêutico. A cirurgia de transgenitalização deve ser concebida como um dentre outros recursos terapêuticos dos quais dispõe o indivíduo transexual em seu processo transexualizador (BRASIL, 2008).

${ }^{4} \mathrm{O}$ transexual é classificado como primário e secundário. O primeiro tipo traduz-se naquele indivíduo que, precocemente, manifesta vontade inequívoca de modificação de sexo. O segundo tipo oscila entre ao homossexualidade e o travestismo. (SÁ; NAVES, 2015, p. 320).
} 
Da mesma forma, interpretar de modo limitado o artigo 58 da Lei de Registros Públicos, que prevê "o prenome será definitivo" (BRASIL, 1973), fere o princípio da dignidade da pessoa humana, um dos fundamentos da República Federativa do Brasil, haja vista que manter os documentos civis dos transexuais em desacordo com sua real identificação é negar-lhe direitos fundamentais.

Felizmente, há decisões judiciais neste sentido, inclusive permitindo a retificação do registro civil sem a necessidade da realização da cirurgia de redesignação de sexo. Veja-se:

\begin{abstract}
APELAÇÃO CÍVEL. RETIFICAÇÃO DO REGISTRO CIVIL. TRANSEXUALISMO. ALTERAÇÃO DO GÊNERO. AUSÊNCIA DE CIRURGIA DE REDESIGNAÇÃO SEXUAL OU TRANSGENITALIZAÇÃO. POSSIBILIDADE. O sexo é físico-biológico, caracterizado pela presença de aparelho genital e outras características que diferenciam os seres humanos entre machos e fêmeas, além da presença do código genético que, igualmente, determina a constituição do sexo - cromossomas XX e XY. O gênero, por sua vez, refere-se ao aspecto psicossocial, ou seja, como o indivíduo se sente e se comporta frente aos padrões estabelecidos como femininos e masculinos a partir do substrato físicobiológico. É um modo de organização de modelos que são transmitidos tendo em vista as estruturas sociais e as relações que se estabelecem entre os sexos. Considerando que o gênero prepondera sobre o sexo, identificando-se o indivíduo transexual com o gênero oposto ao seu sexo biológico e cromossômico, impõe-se a retificação do registro civil, independentemente da realização de cirurgia de redesignação sexual ou transgenitalização, porquanto deve espelhar a forma como o indivíduo se vê, se comporta e é visto socialmente. APELAÇÃO PROVIDA, POR MAIORIA. (BRASIL, 2015) (Grifo nosso) ${ }^{6}$.
\end{abstract}

Neste mês de maio de 2017, a Quarta Turma do Superior Tribunal de Justiça decidiu sobre a possibilidade de modificação do registro civil do transexual sem a necessidade de realização da cirurgia de transgenitalização.

A Quarta Turma entendeu que vários são os motivos que podem levar o transexual a não realizar a cirurgia, como questões financeiras ou de saúde. No caso em julgamento, a recorrente alegou que embora não tenha realizado a cirurgia de mudança de sexo, havia se submetido a intervenções hormonais para adequar a sua aparência física ao seu estado psíquico. (BRASIL, 2017)

\footnotetext{
${ }^{5}$ A Lei 9.708 de 18 de novembro de 1998, mudou a redação do artigo 58 da Lei 6.015 de 31 de dezembro de 1973, passando a vigorar com a seguinte redação: "O prenome será definitivo, admitindo-se, todavia, a sua substituição por apelidos públicos notórios." (BRASIL, 1998).

${ }^{6}$ Tal caso já chegou para análise do Superior Tribunal de Justiça, Recurso Especial no ${ }^{\circ}$ 1.626.739, de relatoria do Ministro Luis Felipe Salomão, ainda pendente de julgamento.
} 
O Ministro Luis Felipe Salomão, além de ter afirmado que é proibida a inclusão do termo transexual no assentamento de nascimento original, ainda que de forma sigilosa, declarou que:

\begin{abstract}
Se a mudança do prenome configura alteração de gênero (masculino para feminino ou vice-versa), a manutenção do sexo constante do registro civil preservará a incongruência entre os dados assentados e a identidade de gênero da pessoa, a qual continuará suscetível a toda sorte de constrangimentos na vida civil, configurando-se, a meu juízo, flagrante atentado a direito existencial inerente à personalidade . (BRASIL, 2017)
\end{abstract}

Conquanto as decisões judicias venham mudando a passos lentos, na dimensão horizontal dos direitos fundamentais há muito o que se modificar, haja vista a extensa e diversa violência contra os transexuais.

Segundo o relatório divulgado pelo Grupo Gay da Bahia, a cada 25 horas alguém pertencente ao grupo LGBTs (lésbicas, gays, bissexuais e transexuais) é assassinado no país. Com certeza, é um dado chocante e não para por aí, "somente em 2016, o ano considerado como o mais violento desde 1970 contra pessoas LGBTs, segundo a entidade, 343 pessoas $^{7}$ foram mortas em todo o Brasil, 32 delas na Bahia” (BRASIL, 2017). O relatoria ainda afirmar que "dos 343 assassinatos, 173 eram gays, 144 trans (travestis e transexuais), 10 lésbicas, 4 bissexuais e 12 heterossexuais (parentes ou conhecidos de LGBTs que foram assassinados por algum envolvimento com eles)" (BRASIL, 2017).

Caso repugnante que ganhou as mídias sociais, inclusive com vídeo no canal de internet You Tube, refere-se a morte da cearense Dandara, de 42 anos, espancada e morta a tiros nas ruas de Fortaleza/CE (LAVOR, 2017).

"Para ONGs que trabalham com a população LGBT, muitos casos de assassinatos de travestis ou transexuais motivadas por ódio e preconceito permanecem impunes" (LAVOR, 2017). Em entrevista, à BBC Brasil o professor Carlos Eduardo Bezerra ${ }^{8}$, respondeu:

\footnotetext{
${ }^{7}$ Este número é ainda maior, pois "é impossível saber quantos transexuais e travestis foram mortos no país, em busca feita nos dados das secretarias de segurança pública. Os Boletins de Ocorrência não geram indicadores baseados em identidade de gênero e orientação sexual. O nome de Dandara, por exemplo, consta no relatório diário de Crimes Violentos Letais Intencionais (CVLI) da Secretaria de Segurança Pública e Defesa Social do Estado do Ceará (SSPDS) como Antônio Cleilson Ferreira Vasconcelos, seu nome de registro de nascimento" (LAVOR, 2017).

${ }^{8}$ Professor e pesquisador do Núcleo de Políticas de Gênero e Sexualidade (NPGS) da Universidade da Integração Internacional da Lusofonia Afro-Brasileira (Unilab) (LAVOR, 2017).
} 
Nada justifica estes crimes. Mas a ausência de políticas públicas efetivas (educação, saúde, emprego, lazer) voltadas para garantir a dignidade e a proteção de pessoas LGBT, sobretudo aquelas mais vulneráveis; a ausência da discussão sobre direitos humanos, gênero e identidade de gênero em escolas e espaços de formação; o avanço do discurso fundamentalista, contribuem para estes tipos de crimes.

Deveras, nada justifica a violência, seja ela psicológica ou física, não somente contra os transexuais, mas a qualquer ser humano. Inconteste que a ausência de políticas públicas sobre gênero e identidade de gênero pode contribuir para ocorrência de crimes, mas a não violação do direito alheio também deve partir de atitudes individuais, a iniciar no seio familiar, respeitando e entendendo o que socialmente, ainda, possa ser considerado diferente.

A educação primária, aquela construída na família e não institucionalmente, deve ser capaz de orientar a formação de um ser humano respeitador, seja a ele próprio seja ao outro. Pais, por exemplo, que forçam os filhos a comportem-se socialmente com o sexo anatômico, ainda que os mesmos tenham sexo psicológico contrário ao morfológico, podem além de oprimirem os filhos, colaborarem para a formação de indivíduos preconceituosos, os quais podem cometer infrações gravíssimas embasadas em crenças pessoais, tomadas como as únicas e as melhores para a maioria.

Por certo, é “impossível traçarmos o que é moralmente recomendado sem oprimirmos grupos e pessoas. Os transexuais não querem um juízo de valor, querem a consideração de que há justiça quando se levam em conta os interesses individuais, a intimidade e a dignidade de cada um" (SÁ; NAVES, 2015, p. 347).

O pintor Einar sofreu bastante para conseguir externalizar a sua "garota dinamarquesa", olhares repulsivos dentro e fora de sua família foram comuns ao seu processo de identificação e transformação em Lili. Na sociedade brasileira, como brevemente demonstrado, tudo que escapa à "estrutura heterossexual" é estigmatizado o que leva, em certos casos, não só à morte psicológica da pessoa, mas também a física.

David Ebershoff, autor de A Garota Dinamarquesa, no posfácil da obra, faz um relato emocionante da sua visão de Lili Elbe:

(...) ela inspirou muitos de nós, tanto trans quanto não, a sermos nós mesmos. Lili sabia que uma vida falsa simplesmente não é vida. Quem somos nós? Quem queremos nos tornar? Como nos percebemos? Como queremos ser percebidos? Estas questões de identidade frequentemente estão no núcleo central de nossos 
conflitos internos. Quem consegue resolvê-las fica mais perto de estar livre. Quase um século atrás, Lili Elbe superou tais questões sobre si mesma. Ela posou para um retrato no ateliê de uma artista e disse para o mundo: -Esta sou eu. (EBERSHOFF, 2016, p. 353)

O que se espera é que o Direito venha corresponder aos direitos dos transexuais, efetivando-se o direito fundamental à saúde psicológica e física, a qual passa, in casu, pelo direito fundamental à sexualidade, permitindo que cada uma possa socialmente manifestar-se como realmente se identifica.

\section{CONCLUSÃO.}

A eficácia vertical dos direitos fundamentais exige dos Poderes Públicos atuações e interpretações ampliativas dos direitos que envolvam os transexuais, com o intuito de efetiválos da melhor maneira possível.

Assim, dois entendimentos devem prevalecer caso tenham sido realizados todos os exames e acompanhamentos psicoterapêuticos, de acordo com a Portaria n. 457, de 19 de agosto de 2008, do Ministério da Saúde e tendo a pessoa indicação para a realização do processo transsexualizador.

O primeiro é que ela possa, caso queira, submeter-se à cirurgia de transgenitalização e, consequentemente, de mudança de prenome.

Como o gênero é uma questão de identidade, o segundo entendimento que deve predominar é o de que, caso o transexual não queira passar pela cirurgia de mudança de sexo, também deve ser a ele franqueado o direito de mudança do prenome, para que este se adeque à sua identidade.

Em ambos os casos, os direitos acima em comento devem ser resguardados, sem a necessidade de autorização judicial, pois caso a transexualidade já esteja plenamente comprovada, por laudos médicos e psicológicos, a mudança de sexo e do prenome, ou apenas a mudança do prenome, fazem parte do projeto de vida digna do transexual.

Da mesma forma, a eficácia horizontal dos direitos fundamentais exige de todas as pessoas o respeito às escolhas e aos caminhos que os transexuais resolveram traçar, afinal, os direitos fundamentais também são efetivados nas relações pessoais quando são adotadas atitudes de inclusão e de não discriminação em relação aos transexuais. 
A todos deve ser franqueada a escolha do caminho que se pretende seguir e ao Direito cabe assegurar que cada um possa se tornar o que realmente é. Não cabe ao Direito interferir nas escolhas pessoais de construção da personalidade, ao revés, ele deve proporcionar meios para a efetivação dessa construção.

Da mesma forma, não deve a sociedade estabelecer o que é moralmente correto, uma vez as pessoas são diferentes e, consequentemente, possuem juízos de valores diversos. Uma sociedade plural deve respeitar a singularidade de cada um e permitir o convívio das diferenças.

\section{REFERÊNCIAS}

ALMEIDA, Gregório Assagra de. Direito Material Coletivo: Superação da Summa Divisio Direito Público e Direito Privado por uma nova Summa Divisio Constitucionalizada. Belo Horizonte: Del Rey, 2008.

ALVARENGA, Juliana Mendonça. Transexualidade e seus reflexos no Direito e Registro Civil. Belo Horizonte: D’Plácido, 2016.

ALVARENGA, Juliana Mendonça; COUTO, Marcelo de Rezende Campos Marinho. Minha vida em Cor-de-Rosa': Uma vida entre dois gêneros. In: Direito e arte: os desafios da pessoalidade. LIMA, Taisa Maria Macena de; SÁ, Maria de Fátima Freire Sá; BERNARDES, Wilba Lúcia Maria. (Org.). Belo Horizonte. Arraes, 2016.

BARROS, Mateus Oliveira. O que são Cisgeneridade e Transgeneridade? In: Gênero, Sexualidade e Direito uma Introdução. Organização: RAMOS, Marcelo Maciel; NICOLI, Pedro Augusto Gravatá; BRENER, Paula Rocha. Belo Horizonte: Initia Via, 2016.

BRASIL. Apelação Cível No 70056132376, Sétima Câmara Cível, Tribunal de Justiça do RS, Relator: Jorge Luís Dall'Agnol, Julgado em 13/11/2013. Disponível em:< http://www.tjrs.jus.br/busca/search?q=cache:www1.tjrs.jus.br/site_php/consulta/consulta_pr ocesso.php\%3Fnome_comarca\%3DTribunal\%2Bde\%2BJusti\%25E7a\%26versao\%3D\%26v ersao_fonetica\%3D1\%26tipo\%3D1\%26id_comarca\%3D700\%26num_processo_mask\%3D7 0056132376\%26num_processo\%3D70056132376\%26codEmenta\%3D5547132++70056132 $376++++\&$ proxystylesheet $=$ tjrs_index\&client $=$ tjrs_index \&ie $=U T F-$

$8 \&$ site $=$ ementario\&access $=$ p \&oe $=$ UTF-

$\underline{8 \& \text { numProcesso=70056132376\&comarca }}=$ Porto\%20Alegre \&dtJulg=13/11/2013\&relator $=\mathrm{J}$ orge\%20Lu\%C3\%ADs\%20Dall\%27Agnol\&aba=juris >. Acesso em 01 maio 2017.

BRASIL. Apelação Cível $N^{o} 70061053880$, Sétima Câmara Cível, Tribunal de Justiça do RS, Relator: Sandra Brisolara Medeiros, Julgado em 24/06/2015. Disponível em:< http://www.tjrs.jus.br/busca/search?q=cache:www1.tjrs.jus.br/site_php/consulta/consulta_pr ocesso.php\%3Fnome_comarca\%3DTribunal\%2Bde\%2BJusti\%25E7a\%26versao\%3D\%26v ersao_fonetica\%3D1\%26tipo\%3D1\%26id_comarca\%3D700\%26num_processo_mask\%3D7 0061053880\%26num_processo\%3D70061053880\%26codEmenta\%3D6361182++70061053 
$880++++\&$ proxystylesheet=tjrs_index\&client=tjrs_index\&ie=UTF-

$8 \&$ site $=$ ementario $\&$ access $=$ p \&oe $=$ UTF -

$8 \&$ numProcesso $=70061053880 \&$ comarca $=$ Comarca $\% 20 \mathrm{de} \% 20$ Panambi\&dtJulg=24/06/201

5\&relator=Sandra\%20Brisolara\%20Medeiros\&aba=juris>. Acesso em 01 maio 2017.

BRASIL. Constituição da República Federativa do Brasil de 1988. Disponível em: <http://www.planalto.gov.br/ccivil_03/constituicao/ConstituicaoCompilado.htm>.Acesso em: 02 abr. 2017.

BRASIL. G1 Portal de Notícias da Globo. BA ocupa $2^{\circ}$ lugar em crimes contra LGBTs, aponta relatório do Grupo Gay. Disponível em:< http://g1.globo.com/bahia/noticia/2017/01/ba-ocupa-2-lugar-em-crimescontra-lgbts-aponta-relatorio-do-grupo-gay.html > Acesso em 01 maio 2017.

BRASIL. G1 Portal de Notícias da Globo. Catar proíbe exibição de 'A garota dinamarquesa', filme sobre transexual. São Paulo, 2016. Disponível em < http://g1.globo.com/poparte/cinema/noticia/2016/01/catar-proibe-exibicao-de-garota-dinamarquesa-filme-sobre-transexual.html> .

Acesso em 23/04/2017.

BRASIL. G1 Portal de Notícias da Globo. STJ decide que transexual pode mudar sexo no RG mesmo sem cirurgia. Brasília, 2017. Disponível em: < http://g1.globo.com/politica/noticia/stjdecide-que-transexual-pode-mudar-sexo-no-rg-mesmo-sem-cirurgia.ghtml >. Acesso em 13 maio 2017.

BRASIL. Lei $n^{\circ} 6.015$ de 31 de dezembro de 1973, dispõe sobre registros públicos e dá outras providências. $\quad$ Disponível em:< http://www.planalto.gov.br/ccivil_03/leis/L6015compilada.htm>. Acesso em 01 maio 2017.

BRASIL. Lei $n^{\circ} 9.708$ de novembro de 1998, altera o art. 58 da Lei $n^{\circ} 6.015$, de 31 de dezembro de 1973, que dispõe sobre Registros Públicos. Disponível em:< http://www.planalto.gov.br/ccivil_03/leis/L9708.htm>. Acesso em 01 maio 2017.

BRASIL. Portaria $n^{o} 457$ de 19 de agosto de 2008. Disponível em:< http://bvsms.saude.gov.br/bvs/saudelegis/sas/2008/prt0457_19_08_2008.html>. Acesso em 01 maio 2017.

BRASIL. Superior Tribunal de Justiça. Transexuais têm direito à alteração do registro civil sem realização de cirurgia. Brasília, 2017. Disponível em: < http://www.stj.jus.br/sites/STJ/default/pt_BR/Comunica\%C3\%A7\%C3\%A3o/noticias/Not\%C 3\%ADcias/Transexuais-t\%C3\%AAm-direito-\%C3\%A0-altera\%C3\%A7\%C3\%A3o-doregistro-civil-sem-realiza\%C3\%A7\%C3\%A3o-de-cirurgia> Acesso em 13 maio 2017.

CANÇADO, Paula Oliveira Mascarenhas. O Programa Vila Viva: Análise dos Obstáculos e Problemas à Luz dos Objetivos Fundamentais da República Federativa do Brasil e do Direito Processual Coletivo como Novo Ramo do Direito Processual. 2014. 174f. Dissertação (Mestrado em Direito) - Faculdade de Direito, Fundação Universidade de Itaúna, Itaúna, 2014. 
DIMOULIS, Dimitri; MARTINS, Leonardo. Teoria Geral dos Direitos Fundamentais. $2^{\mathrm{a}}$ ed. rev.; atual. e ampliada; $2^{a}$ tiragem. São Paulo: Revista dos Tribunais, 2009.

EBERSHOFF, David. A Garota Dinamarquesa. Rio de Janeiro: Fábrica231, 2016.

FERNANDES, Bernardo Gonçalves. Curso de Direito Constitucional. Conforme EC 88/2015.

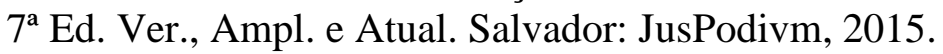

HESSE, Konrad. Elementos de Direito Constitucional da República Federal da Alemanha. Porto Alegre: Sergio Antonio Fabris Editor, 1998.

JESUS, Jaqueline Gomes de. Orientações Sobre Identidade de Gênero: Conceitos e Termos. Brasília, 2012.

Disponível em: $<$ https://www.sertao.ufg.br/up/16/o/ORIENTA\%C3\%87\%C3\%95ES_SOBRE_IDENTID ADE_DE_G\%C3\%8ANERO_CONCEITOS_E_TERMOS_2\%C2\%AA Edi\%C3\%A7\%C3\%A3o.pdf?1355331649> Acesso em 28 mar. 2017.

RIOS, Roger Raupp. Direito da Antidiscriminação, Sexo, Sexualidade e Gênero: A Compreensão da Proibição Constitucional de Discriminação por Motivo de Sexo. In: SARMENTO,D.; IKAWA, D., PIOVESAN, F. Igualdade, Diferença e Direitos Humanos. Rio de Janeiro:2010.

LAVOR, Thays. 'Meu filho vivia sendo humilhado': caso Dandara expõe tragédia de viver e morrer travesti no Brasil. BBC Brasil. Disponível em: $<$ http://www.bbc.com/portuguese/brasil$\underline{39227148}$ > Acesso em 01 maio 2017.

SÁ, Maria de Fátima Freire de; NAVES, Bruno Torquato de Oliveira Naves. Manual de Biodireito. Belo Horizonte. Del Rey, 3 ed., 2015.

SANTOS, Lohana Morelli Tanure. O que é transexualidade? In: Gênero, Sexualidade e Direito uma Introdução. Organização: RAMOS, Marcelo Maciel; NICOLI, Pedro Augusto Gravatá; BRENER, Paula Rocha. Belo Horizonte: Initia Via, 2016.

SOLOMON, Andrew. Longe da Árvore. Pais, filhos e a busca da identidade. São Paulo: Companhia das Letras, 2013 